\title{
Influence of Supporting Electrolytes on RO 16 Dye Electrochemical Oxidation Using Boron Doped Diamond Electrodes
}

\author{
Fernanda Lanzoni Migliorini ${ }^{a *}$, Andrea Boldarini Couto ${ }^{a}$, Suellen Aparecida Alves ${ }^{c}$, \\ Marcos Roberto de Vasconcelos Lanza $a^{b}$, Neidenêi Gomes Ferreira ${ }^{a}$ \\ ${ }^{a}$ Instituto Nacional de Pesquisas Espaciais- INPE, 12201-970, São José dos Campos - SP, Brazil \\ ${ }^{b}$ Instituto de Química de São Carlos - IQSC, Universidade de São Paulo - USP, 13560-970, \\ São Carlos, SP, Brazil \\ ${ }^{c}$ Laboratório Interdisciplinar de Eletroquímica e Cerâmica- LIEC, Universidade Federal de \\ São Carlos, 13565-905, São Carlos, SP, Brazil
}

Received: February 23, 2016; Revised: December 15, 2016; Accepted: February 13, 2017

\begin{abstract}
The influence of different supporting electrolytes as well as of different current densities on RO16 dye electrochemical oxidation using BDD electrodes has been systematically studied. The RO16 azo-dye electrooxidation experiments were performed at different current densities and three different supporting electrolytes: $\mathrm{H}_{2} \mathrm{SO}_{4} 0.1 \mathrm{~mol} \mathrm{~L}^{-1}, \mathrm{HClO}_{4} 0.1 \mathrm{~mol} \mathrm{~L}^{-1}$ and $\mathrm{K}_{2} \mathrm{SO}_{4} 0.1 \mathrm{~mol} \mathrm{~L}^{-1}$. The results showed that a higher degradation for reactive azo dye $\mathrm{RO} 16$ was observed for the $\mathrm{K}_{2} \mathrm{SO}_{4}(\mathrm{pH}=10)$ supporting electrolyte for a current density of $100 \mathrm{~mA} \mathrm{~cm}^{-2}$. This behavior can be associated with the deprotonation effect of the dye molecule, which can facilitate breakdown of the molecule, specifically the azo bond making color removal more efficient. In addition, in this $\mathrm{pH}$ there is a greater amount of hydroxyl ion $\left(\mathrm{OH}^{-}\right)$available increasing the hydroxyl radical formation.
\end{abstract}

Keywords: Electrochemical Oxidation, Boron Doped Diamond, Reactive Orange 16 Dye, Electrolyte Influence, $\mathrm{pH}$

\section{Introduction}

Large amounts of different dyes are usually used in the textile industry. The textile wastewaters have characteristics such as strong color, large number of suspended solids, fluctuating $\mathrm{pH}$, high chemical oxygen demand (COD), and biological toxicity ${ }^{1}$. These characteristics contribute to turn this kind of effluent into an environmental problem. Most of these problems are due to the nature of the organic molecules that compose the dyes present in textile wastewaters. In this context, azo-dyes form a large group of organic molecules and represent the largest class of dyes mainly used in textile processing $^{2-4}$. The toxicological hazards of synthetic dyes for human health are intrinsically related to the mode and the time of exposure, such as oral ingestion, skin sensitization, and respiratory sensitization. Biotransformation of these dyes may be responsible for the formation of amines, benzidine and other intermediates with mutagenic and carcinogenic character $^{3}$. Thus, dye residue can be highly toxic when present in any living organism, and most of these problems are due to the nature of the organic molecules that make up the dyes. Dye presence can be easily detected, even at low concentrations where they are practically invisible. When these effluents are discharged into the water, they can cause serious problems by changing the natural color of rivers and their biological cycles, which may also interfere in the photosynthesis process 5 .

Thus, new technologies for wastewater treatment have been studied to eliminate or minimize this problem. Among

* e-mail: fernandamigliorini@yahoo.com.br them, Advanced Oxidation Processes (AOP) have appeared as an efficient alternative methodology to selectively decompose many organic compounds ${ }^{5-11}$. These processes are characterized by the transformation of a large number of organic pollutants into carbon dioxide, water and inorganic anions through the degradation reactions involving oxidative transitory species, mainly the hydroxyl $\operatorname{radical}(\bullet \mathrm{OH})$. AOP have been used to electrochemically produce hydroxyl radicals in an anodic reaction directly from water ${ }^{12}$. These hydroxyl radicals strongly react with all organic substances usually by hydrogen abstraction ${ }^{12}$. In addition to its environmental compatibility, the electrochemical process presents important advantages related to its versatility, high energy efficiency, amenability of automation, and safety because it operates at mild conditions ${ }^{13-15}$. Electrochemical oxidation with different anodes and indirect electro-oxidation is a typical method for the removal of dye pollutants. It is classified as electrochemical advanced oxidation process (EAOP) and consists of the oxidation of pollutants in an electrolytic cell by chemical reaction with electrogenerated species from the water discharge at the anode.

The boron-doped diamond (BDD) thin film seems to be a suitable electrode material to produce hydroxyl radicals by the electrochemical method. The BDD based anode is a new electrode material which has received great attention in the field of wastewater treatment for its wide potential window, low background current, very low activity for $\mathrm{O}_{2}$ evolution reaction and high anodic potential ${ }^{16}$. Another advantage of using BDD electrodes for organic degradation is related to their inertness, which prevents some undesirable by-products or products that would be strongly adsorbed on 
the anode surface. In most cases, just by rinsing the BDD surface with an appropriate solvent is enough to remove the adsorbed species. For surface passivators, such as chlorophenols ${ }^{17}$, nitrophenol, and aromatic amines ${ }^{17,18}$ this problem is solved just by applying high anodic or cathodic potentials during the electrochemical procedure. The BDD electrode is considered a "non-active" anode ${ }^{19}$. In general, the accepted reactions for the mechanism involved in the mineralization of organic pollutants $(\mathrm{R})$ on the BDD, at the anode active sites (M) and in aqueous solutions, lead to the production of adsorbed hydroxyl radicals $(\mathrm{M}(\bullet \mathrm{OH})$ ads $)$ at the BDD anode surface, which is directly responsible for the generation of the mineralization products.

Our research group has published papers about organic compounds electrooxidation, especially textile dyes, for instance, a paper about Reactive Orange 16 (RO16) dye degradation using different BDD electrodes (acceptor concentrations of 4.0 and $8.0 \times 10^{21}$ atoms $\mathrm{cm}^{-3}$ ). We noticed that both BDD electrodes presented efficiency and high stability in acidic medium ${ }^{20}$. However, the study did not report the electrolyte effect in RO16 degradation. It is known that both the $\mathrm{pH}$ and the electrolyte nature can influence the degradation process. These parameters can affect the efficiency degradation due to generating other oxidizing species that can improve the removal process and also change the characteristics of the molecule (protonation/deprotonation, for example). Thereby, this paper aims at evaluating the influence of supporting electrolyte in the electrochemical degradation of RO16 dye using BDD grown on titanium substrate (BDD/Ti). This study was conducted under different current densities and different supporting electrolytes, with controlled degradation temperature. The results were analyzed using analytical techniques such as UV-VIS spectroscopy, high-pressure liquid chromatography (HPLC) and total organic carbon (TOC) analyses.

\section{Experimental}

\subsection{Preparation and characterization of $B D D / T i$ electrodes}

The BDD electrode was grown on Ti substrate by hot filament chemical vapor deposition (HFCVD) technique. The deposition of diamond on titanium has a singular characteristic attributed to the strong stress formation between the film and the substrate, which arises from extrinsic and intrinsic factors. In this sense, some pre- treatments on the substrate surface are required to decrease the stress and to increase the nucleation rate ${ }^{21-23}$. Among them, the mechanical incision is effective to increase the titanium surface area and roughness besides improving the mechanical anchoring of the film. This incision was made in air abrasion with glass beads. The treated surface ensures the best adhesion of the diamond coating due to its high effective area for the film deposition. The BDD/Ti with dimensions of $2.5 \times 2.5 \times 0.5$ $\mathrm{mm}$ was grown from a standard gas mixture consisting of $99 \%$ of $\mathrm{H}_{2}$ and $1 \%$ of $\mathrm{CH}_{4}$. The temperature and pressure inside the chamber reactor were kept at $650{ }^{\circ} \mathrm{C}$ and at 40 Torr, respectively. The sample was grown for $16 \mathrm{~h}$. The doping control was obtained from an additional $\mathrm{H}_{2}$ gas flux passing through a bubbler containing a solution of $\mathrm{B}_{2} \mathrm{O}_{3}$ dissolved in $\mathrm{CH}_{3} \mathrm{OH}$ with the $\mathrm{B} / \mathrm{C}$ ratio of $15.000 \mathrm{ppm}$. The additional hydrogen flow into the reactor was controlled by a rotameter which was kept at $40 \mathrm{sccm}$ (standard centimeter cubic per minute). The top view SEM images of BDD/Ti films were obtained from a Jeol equipment JSM-5310. The quality of BDD/Ti films were analyzed from Micro-Raman spectra recorded by a Renishaw microscope system 2000 in backscattering configuration. The diamond patterns in addition to hydrides and titanium carbides phases were monitored by grazing incident X-ray diffraction (GIXRD) using a Philips X'Pert diffractometer.

\subsection{Electrochemical degradation of Dye RO16}

The electrochemical degradation of RO16 azo-dye solution supplied by Aldrich $(\sim 50 \% \mathrm{~m} / \mathrm{m})$ was performed in a polypropylene home-made single cell with capacity of $0.45 \mathrm{~L}$. The BDD/Ti working electrode $\left(\sim 4.15 \mathrm{~cm}^{2}\right.$ of the geometric area) was located at the bottom of the cell. A platinum screen, $2 \mathrm{~cm}$ in diameter, was used as a counter electrode and a commercial $\mathrm{Ag} / \mathrm{AgCl}$ electrode $\left(3.0 \mathrm{~mol} \mathrm{~L}^{-1}\right.$ $\mathrm{KCl}$ solutions) was used as reference. All the degradation experiments were performed at $25^{\circ} \mathrm{C}$ and at constant stirring and were carried out considering two steps. Firstly, the eletrooxidation was performed under galvanostatic mode, at a fixed current density of $50 \mathrm{~mA} \mathrm{~cm}^{-2}$ using $150 \mathrm{mg} \mathrm{L}^{-1}$ of the RO16 azo-dye varying the supporting electrolytes: $\mathrm{H}_{2} \mathrm{SO}_{4}$ $0.1 \mathrm{~mol} \mathrm{~L}^{-1}, \mathrm{HClO}_{4} 0.1 \mathrm{~mol} \mathrm{~L}^{-1}, \mathrm{~K}_{2} \mathrm{SO}_{4} 0.1 \mathrm{~mol} \mathrm{~L}^{-1} \mathrm{pH}=6.5$ and $\mathrm{K}_{2} \mathrm{SO}_{4} 0.1 \mathrm{~mol} \mathrm{~L}^{-1} \mathrm{pH}=10$ (pHmeter pHB 500 Benchtop $\mathrm{pH}$ Meter). Secondly, the solution that presented the best performance in the previous step was used to investigate the influence of different current densities of 25, 50, 75 and 100 $\mathrm{mA} \mathrm{cm}^{-2}$. All electrochemical measurements were carried out using a potentiostat/galvanostat AUTOLAB model PGSTAT 302 (Eco Chimie) coupled with a BRTS-10A current booster, controlled by the GPES software.

\subsection{Instrumentation and analytical conditions}

Concentration analyses of RO16 azo-dye were carried out using high pressure liquid chromatography (HPLC) Shimadzu 20A with UV/Vis detector SPD-20A. The stationary phase used was a reverse phase columm $\left(\mathrm{C}_{18}\right.$ Varian Pursuit $5250 \times 4.6 \mathrm{~mm}$ ) while the mobile phase was ammonium acetate/methanol with a proportion of 70:30 and flow of $0.8 \mathrm{~mL} \mathrm{~min}^{-1}$ for wavelength of the $249 \mathrm{~nm}$ at $40{ }^{\circ} \mathrm{C}$. The Total Organic Carbon (TOC-VCPN Shimadzu) technique 
was employed to determine the removed organic material. The UV-Vis spectra were recorded in Varian Cary 50 Scan spectrometer in the range from 300 to $600 \mathrm{~nm}$ with quartz cubet ( $1 \mathrm{~cm}$ of the optic path). The maximum absorption used to calculate the concentration by UV/Vis was at 388 nm wavelength.

\section{Results and Discussions}

\subsection{Morphological and structural characterization of diamond electrode}

The top view SEM image of the BDD/Ti electrode is shown in Figure 1. The image shows a continuous and homogeneous film covering the whole substrate without the presence of delamination and cracks, which is a strong indicative of its high adherence. This is an important result because diamond growth on $\mathrm{Ti}$ substrates presents two problems. The first one is related to the difference in the thermal expansion coefficients between $\mathrm{Ti}$ and diamond. The second is associated to the formation of intermediate phases such as hydride and titanium carbide. These factors together weaken the samples and they are responsible for the formation of cracks and delamination in diamond film ${ }^{24}$.

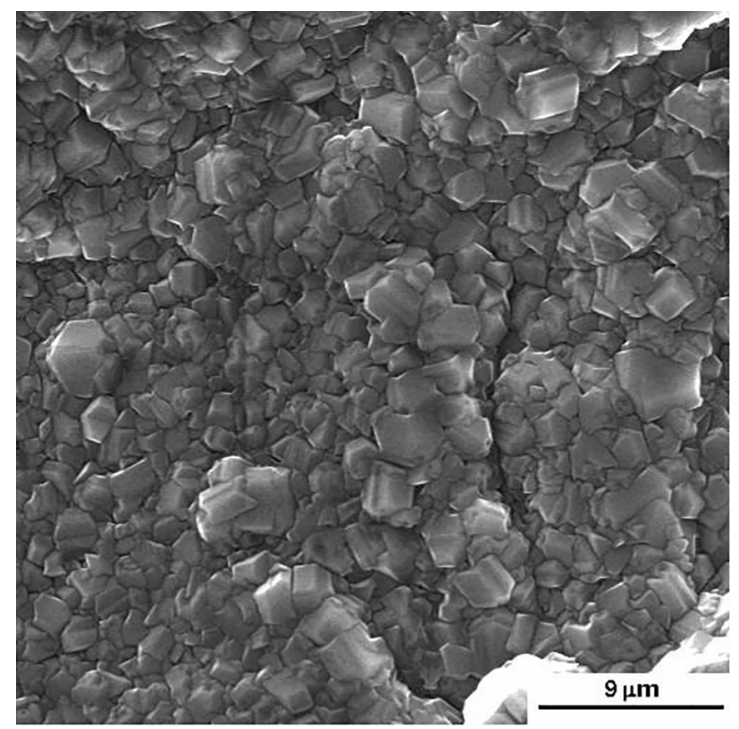

Figure 1. Scanning electron micrograph of diamond film grown on titanium substrate with $15000 \mathrm{ppm} \mathrm{B/C}$.

To investigate the composition and the quality of BDD/ Ti film, Raman's scattering spectra were registered and are shown in Figure 2. The presence of a Raman peak at around $1332 \mathrm{~cm}^{-1}$ was verified, which corresponds to the diamond first-order phonon vibration. The emergent band at 1200 $\mathrm{cm}^{-1}$ was also observed, characteristic of the boron doped diamond films, which is attributed to the induced disorder in the diamond structure due to the boron incorporation ${ }^{25-27}$. By increasing the doping level this band increases significantly and a drastic reduction in the diamond peak is observed. This process is assigned to the relaxation of selection rule $\mathrm{k}=0$ of Raman scattering due to the presence of a very high concentration of boron in the diamond lattice ${ }^{25}$. The band around $1580 \mathrm{~cm}^{-1}$ can be attributed to $\mathrm{G}$ band (graphitic phases). The appearance of a band at around $500 \mathrm{~cm}^{-1}$ is also observed, attributed to the vibration of boron pairs in diamond lattice ${ }^{27}$.

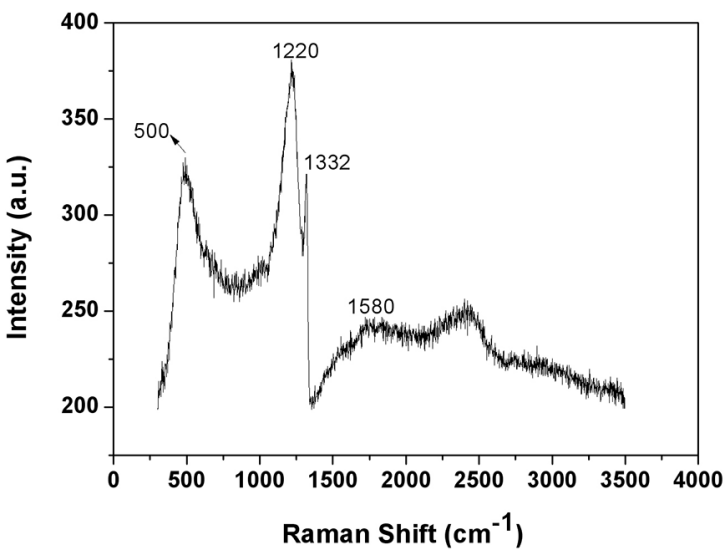

Figure 2. Raman spectra of diamond films grown on titanium substrates with $15000 \mathrm{ppm} \mathrm{B/C}$.

X-ray diffraction results are shown in Figure 3 and were collected in the incidence angle of $1^{\circ}$ over the range from $30^{\circ}$ to $80^{\circ}$. For this geometry, the grazing incident X-ray diffraction (GIXRD) and the oblique angle to the penetration depth of the X-rays are largely reduced, facilitating the identification of different phases present in the BDD film. Another feature of this method is that the illumination of a large sample area allows the detection of thin layers that may be present in the film/substrate interface such as carbides (TiC) and hydrides (TiH). For all sample sets studied, the patterns clearly depict the $2 \theta$ peaks at $75.5^{\circ}$ and at $44^{\circ}$ corresponding to the (111) and the (220) diamond diffraction planes, respectively assuring the material crystallinity. The diffractograms also show the formation of $\mathrm{TiC}$ phase related to the peaks $<111>,<200>,<220>$ and $<311>$. The TiH phase was associated to peaks $<114>$ and $<110>$, and the $\mathrm{TiH}_{2}$ phase to $<111>$. Besides, the Ti phase was observed in the peaks $<100>,<002>,<101>,<102>,<110>$ and $<103>25$. As previously discussed, the growth of diamond films on $\mathrm{Ti}$ substrate is challenging. During the deposition of diamond, carbon and hydrogen present in the gas atmosphere diffuse into the titanium matrix forming $\mathrm{TiH}$ and $\mathrm{TiC}$ phases. As observed in the diffractograms, the formation of these phases is directly related to growing conditions. Thus, it is very important to optimize the experimental parameters to grow diamond films on titanium substrates with good quality and adherence. 


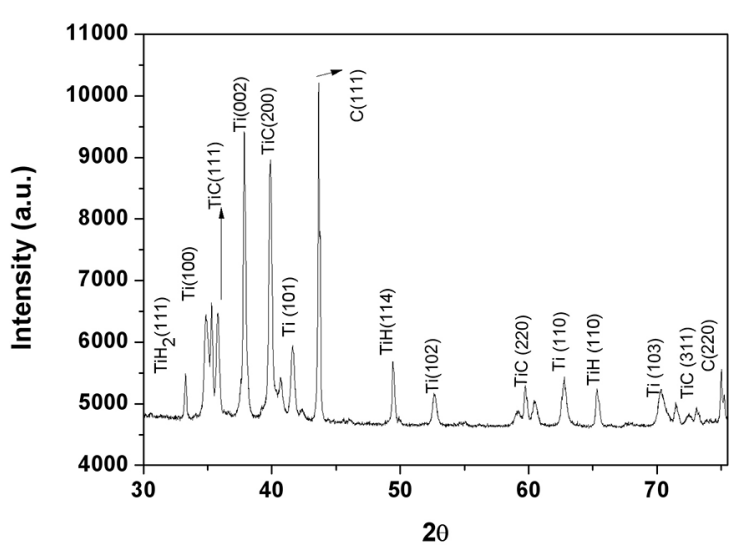

Figure 3. X-ray diffraction of diamond films grown on titanium substrates with $15000 \mathrm{ppm} \mathrm{B/C}$.

\subsection{Electrochemical degradation of the dye RO16}

\subsubsection{Support electrolyte effect on the RO16 dye degradation}

The influence of the electrolyte composition in the BDD/ electrolyte interface is an important experimental parameter to be considered in organic pollutant electrooxidation processes. Hence, the electrochemical degradation behavior of the RO16 dye was investigated in four different electrolytes of $\mathrm{H}_{2} \mathrm{SO}_{4}$, $\mathrm{HClO}_{4}, \mathrm{~K}_{2} \mathrm{SO}_{4}(\mathrm{pH}=6.5)$, and $\mathrm{K}_{2} \mathrm{SO}_{4}(\mathrm{pH}=10)$ in order to evaluate the electrolyte influence as well as its $\mathrm{pH}$ on these oxidation processes. The dye electrooxidation results were examined by UV-Vis and TOC measurements.

Firstly, the influence of supporting electrolyte was conducted using the same counter ion in acid $\mathrm{pH}$ solutions of $\mathrm{H}_{2} \mathrm{SO}_{4}$ and $\mathrm{HClO}_{4}$. These studies focused on the interference of the electrolyte anion on the dye electrooxidation. Figure 4 (A and B) presents the decay of the RO16 azodye as a function of the electrolysis time at $50 \mathrm{~mA} \mathrm{~cm}^{-2}$ current density. The absorption spectrum of RO16 azo-dye is characterized by two bands, associated to their intense orange color. The first is located in the UV region, with its maxima at $390 \mathrm{~nm}$, and the second is located in the visible region at $500 \mathrm{~nm}$. The absorbance band at $500 \mathrm{~nm}$ is due to the $n-\pi^{*}$ transitions of chromophobic azo group $(-\mathrm{N}=\mathrm{N}-)$ present in the RO16 molecules and the band at $390 \mathrm{~nm}$ is due to the $\pi-\pi^{*}$ transitions related to the aromatic rings bonded to the azo group ${ }^{28}$. By comparing the decay of these two bands, a strong influence of the supporting electrolyte in the dye electrooxidation process was observed. The intensity reductions of the two azo dye absorbance bands were approximately $29 \%$ for $\mathrm{H}_{2} \mathrm{SO}_{4}$ supporting electrolyte and $9 \%$ for the solution containing $\mathrm{HClO}_{4}$. This behavior can be explained through the model proposed by Comninellis ${ }^{29}$. According to this model, the first step in the oxidation of the organic compound is the water discharge on the electrode surface by producing hydroxyl radicals (Equations 1 and 2):

$$
\begin{gathered}
\mathrm{H}_{2} \mathrm{O} \rightarrow \mathrm{H}^{+}+\mathrm{OH}^{-} \\
\mathrm{H}^{+}+\mathrm{OH}^{-} \rightarrow \cdot \mathrm{OH}+\mathrm{H}^{+}+\mathrm{e}^{-}
\end{gathered}
$$
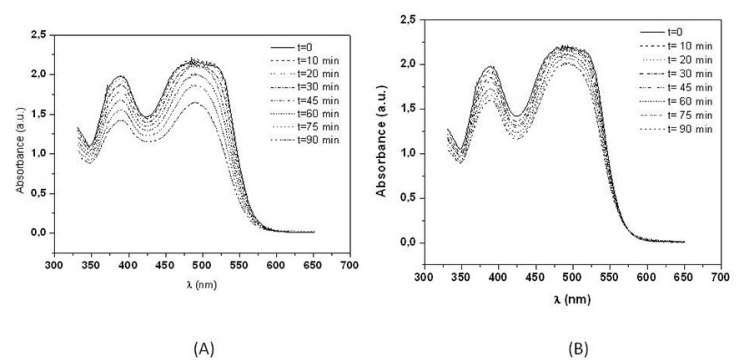

Figure 4. Absorption spectra of RO16 dye solutions at $50 \mathrm{~mA}$ $\mathrm{cm}^{-2}$ (a) $\mathrm{H}_{2} \mathrm{SO}_{4}$ and (b) $\mathrm{HClO}_{4}$, as a function of electrolysis time.

However, other electrogenerated oxidants can be formed depending on the characteristics of the supporting electrolyte. These oxidizing agents can participate in the electrooxidation of organic compounds in the region close to the anode surface and/or in the bulk of the electrolyte. Considering these two supporting electrolytes, the following reactions can be involved on BDD anodes ${ }^{29}$ :

$$
\begin{gathered}
3 \mathrm{H}_{2} \mathrm{O} \rightarrow \mathrm{O}_{3}+6 \mathrm{H}^{+}+6 \mathrm{e}^{-} \\
2 \mathrm{H}_{2} \mathrm{O} \rightarrow \mathrm{H}_{2} \mathrm{O}_{2}+2 \mathrm{H}^{+}+2 \mathrm{e}^{-}
\end{gathered}
$$

Particularly for the $\mathrm{H}_{2} \mathrm{SO}_{4}$ supporting electrolyte the following reaction also occurs:

$$
2 \mathrm{HSO}_{4}^{-} \rightarrow \mathrm{S}_{2} \mathrm{O}_{8}^{2-}+2 \mathrm{H}^{+}+2 \mathrm{e}^{-}
$$

Thus, it can be assumed that the value differences obtained using these two supporting electrolytes is associated to the presence of peroxodisulfate anions that attack the chromophore groups improving the electrolytic process. The TOC analysis, presented difference in the TOC removal values of $14 \%$ for $\mathrm{H}_{2} \mathrm{SO}_{4}$ supporting electrolyte and $8 \%$ for the electrolyte containing $\mathrm{HClO}_{4}$.

The literature reports that ions $\mathrm{SO}_{4}^{2-}, \mathrm{ClO}_{4}^{-}$and $\mathrm{Cl}^{-}$can improve eletrooxidation process using $\mathrm{BDD}$ electrodes ${ }^{29}$. The use of electrolyte containing $\mathrm{Cl}^{-}$ions increases the efficiency degradation of the organic compounds due to the formation of $\mathrm{Cl}_{2}$, however, the formation of chlorinated compounds may occur. This way, electrolyte containing $\mathrm{Cl}^{-}$was not used in this study. For $\mathrm{HClO}_{4}$ as supporting electrolyte the main reaction is $\mathrm{H}_{2} \mathrm{O}_{2}$ formation (equation 4). This specie can diffuse to bulk of the solution or can be oxidized (with oxygen evolution). The removal kinetic using $\mathrm{H}_{2} \mathrm{O}_{2}$ is very slow. Thus, this specie did not directly influenced the removal process. Besides, for $\mathrm{HClO}_{4}$ solution the electrode presented delaminations during the electrolysis processes. According to the literature, this medium can cause the electrode corrosion due to $\mathrm{Cl}_{2}$ formation of following mechanism below ${ }^{30,31}$ : 


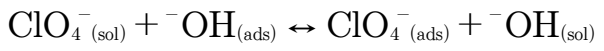

$$
\begin{aligned}
& \mathrm{ClO}_{4}^{-}\left(\text {(ads) } \rightarrow \text { int ermediates } \rightarrow \mathrm{Cl}^{-}{ }_{(\text {ads })} \leftrightarrow \mathrm{Cl}^{-}{ }_{(\text {sol) }}\right. \\
& \mathrm{Cl}^{-}(\mathrm{sol}) \leftrightarrow \mathrm{Cl}_{2(\mathrm{sol})}+2 \mathrm{e}^{-}
\end{aligned}
$$

Thus, both TOC and colour removal presented lower efficiency when compared to those using $\mathrm{H}_{2} \mathrm{SO}_{4}$ supporting electrolyte. Considering the above results a new study was carried out fixing the anion sulfate $\left(\mathrm{SO}_{4}^{2-}\right)$ and varying the $\mathrm{pH}$ of the medium in order to investigate the $\mathrm{pH}$ effect on the RO16 dye eletrooxidation. For this purpose, two different initial $\mathrm{pH}$ values were investigated. The results are shown in Figure 5 (A and B) corresponding to neutral and basic medium, respectively. The absorption spectrum of RO16 azo-dye revealed a significant increase in the decay of the intense dye orange color according to the following order: acid $\mathrm{pH}<$ neutral $\mathrm{pH}<$ basic $\mathrm{pH}$. The alkaline medium ( $\mathrm{pH} 10)$ proved to be more favorable with respect to color removal. Intensities reduction of the two azo dye absorbance bands was $96 \%$ using basic $\mathrm{pH}$, whereas for neutral medium it was $65 \%$. The $\mathrm{pH}$ influence is an important parameter for the electrochemical oxidation process. However, there is no consensus about $\mathrm{pH}$ solution and degradation efficiency. Indeed, the variation of the degradation efficiency with $\mathrm{pH}$ is associated with the organic compound $\left(\mathrm{pK}_{\mathrm{a}}\right.$, structure and surface charge) and the $\cdot \mathrm{OH}$ radicals generation ${ }^{9}$. Flox et al. studied the oxidation of 4,6-dinitro-o-cresol (DNOC) with BDD electrodes with different $\mathrm{pH}$ values (2.0-12.0). The authors observed that total organic carbon is more rapidly removed in acid medium $(\mathrm{pH} 3.0){ }^{10}$. On the other hand, Costa et al. evaluate the electrooxidation of acid black 210 dye with BDD electrode under different $\mathrm{pH}$ condictions and they observed that the best performance was obtained in $\mathrm{pH} 11.7^{11}$. In the present study, both effects may influence the improved performance degradation in basic medium. In basic medium the RO16 dye presents in deprotonated form (Figure 6). This form is more susceptible to azo bond break and as consequence, the color removal is more efficient ${ }^{12,13}$. Furthermore, the discoloring ability of this method depends on the amount of the hydroxyl radical (main oxidizing agent) generated on the anode surface. According to the first step of the oxidation proposed above, the hydroxyl radical is formed by the loss of one electron from the hydroxyl ion. In basic medium, there is a greater amount of available hydroxyl ion $\left(\mathrm{OH}^{-}\right)$so that its presence increases the hydroxyl radical formation. Consequently, it accelerates the RO16 dye eletrooxidation rate. On the other hand, the worst performance in acid $\mathrm{pH}$ may be ascribed to a poor hydroxyl radical generation possibly caused by the neutralization reaction of $\mathrm{H}^{+}$ion (in excess from acid) with the hydroxyl ion (from water discharge), reducing the generation of hydroxyl radical on the electrode surface. It is noteworthy that TOC removal is almost the same to all
$\mathrm{pH}$ studied. This result may indicate more contribution to molecule form (protonated/deprotonated) in the color removal than that related with the generation of hydroxyl radical since that there is no significant difference in the mineralization of the organic matter.

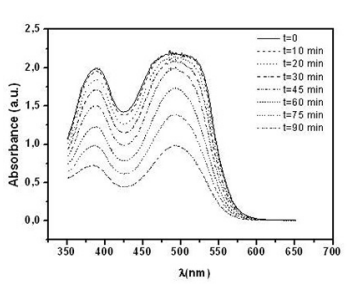

(A)

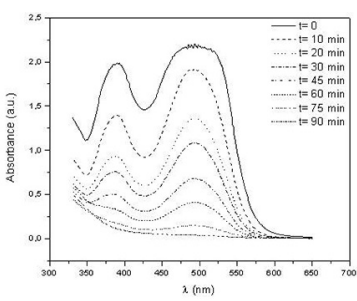

(B)
Figure 5. Absorption spectra of RO16 dye solutions at $50 \mathrm{~mA} \mathrm{~cm}^{-2}$ (a) $\mathrm{K}_{2} \mathrm{SO}_{4}$ and (b) $\mathrm{K}_{2} \mathrm{SO}_{4} \mathrm{pH}=10$, as a function of electrolysis time.

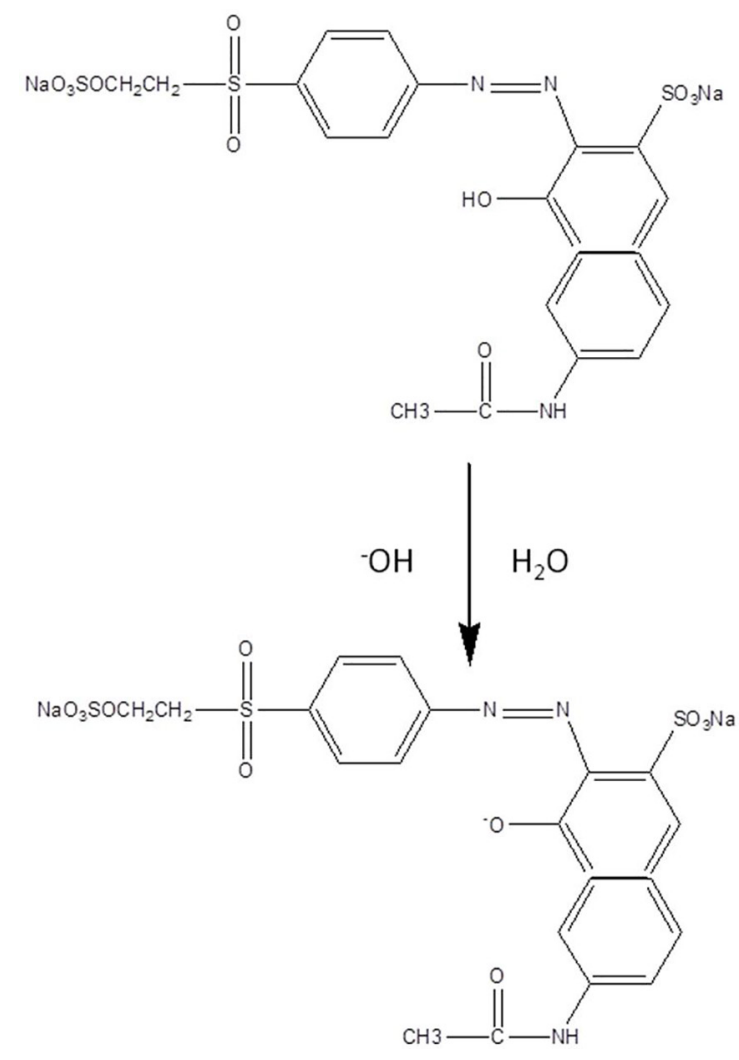

Figure 6. RO16 dye protonated/deprotonated structure.

\subsubsection{Effect of current density in the dye RO16 degradation}

The best response for the electrooxidation was obtained at $\mathrm{pH}=10$. From these results and under the same experimental conditions the role of current density was investigated. The electrodegradation were performed at different current densities of 25, 50, 75 and $100 \mathrm{~mA} \mathrm{~cm}{ }^{-2}$. The aromatic compound concentrations on the RO16 azo-dye solution 
decreased exponentially as a function of the electrolysis time. This behavior was observed for all current densities performed during the electrolysis and was progressively more pronounced as the current density was enhanced. The exponential profile of the RO16 azo-dye absorbance curves as a function of the time point to a pseudo-first order kinetic for the reactions involved in the eletrodegradation of this colorant (Figure 7). The apparent kinetic constant $\left(\mathrm{k}_{\mathrm{app}}\right)$ can be linked to the dye concentration by the Equation 9 .

$$
\ln \frac{[\text { Corant }]}{[\text { Corant }]_{0}}=-k_{\text {app }} t
$$

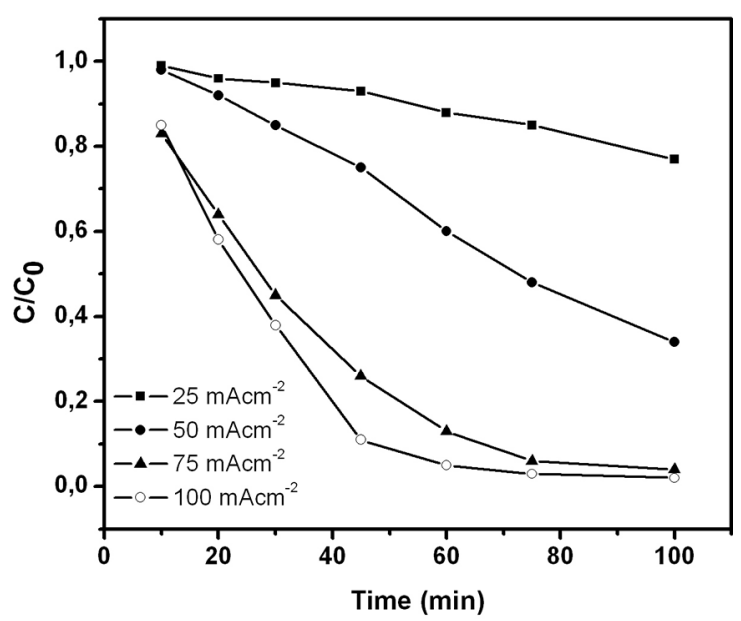

Figure 7. The concentration decay curves $(\lambda=388 \mathrm{~nm})$ as a function the time.

where [Corant] is the dye concentration at time $t$, [Corant $]_{0}$ is the initial dye concentration, and $\mathrm{k}_{\text {app }}$ is the rate constant.

The $\mathrm{k}_{\text {app }}$ as a function of the applied current density is shown in Figure 8. The pseudo first-order rate constant obtained increased as a function of the current density because of the constant generation of $\bullet \mathrm{OH}$. Moreover, concentration decay followed an exponential trend due to mass-transport limitation.

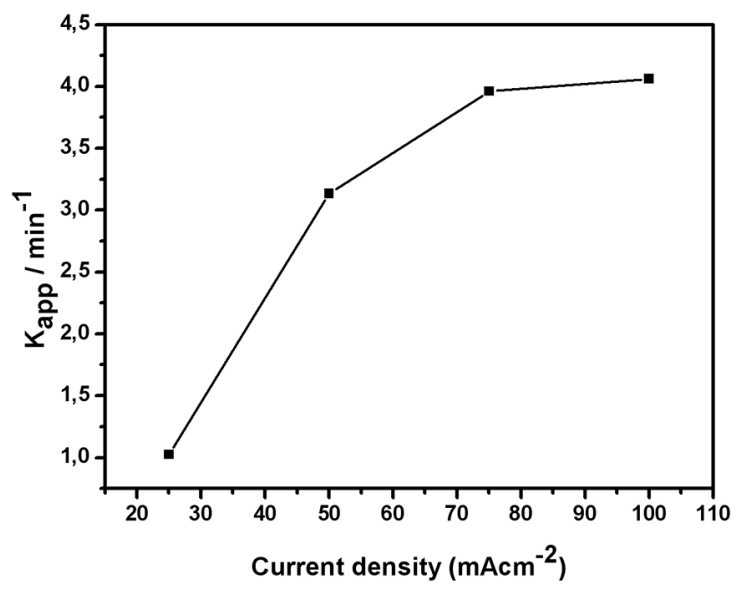

Figure 8. Kinetic constant variation from RO16 azo-dye electrodegradation process as a function of the applied current density.

\subsubsection{TOC Measurements}

TOC analyses were used to quantify the organic load present at the end of each RO16 dye electrochemical degradation process. The efficiency of electrochemical process to mineralize the organic matter present in the dye solution is observed in this analysis. We calculated the efficiency of mineralization at the end of each electrolysis in the whole range of current densities studied (Figure 9) according to the Equation 10:

$$
M E=\frac{\left(\text { TOC }_{\text {initial }}-T C_{\text {final }}\right)}{\text { TOCinitial }} \chi 100
$$

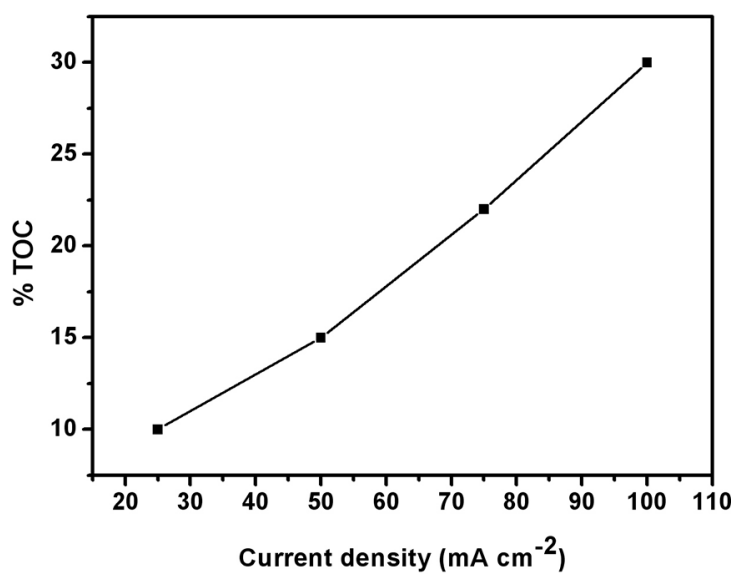

Figure 9. TOC removal efficiency as a function of the applied current densities during the electrodegradation process.

The mineralization efficiency of this organic compound increased as a function of applied current density. The TOC removal of 10, 15, 22 and 30\% were obtained for current densities of $25,50,75$ and $100 \mathrm{~mA} \mathrm{~cm}^{-2}$, respectively.

\subsubsection{HPLC qualitative detection}

The aromatic intermediates produced during each electrochemical treatment containing RO16 dye were detected by high performance liquid chromatography (HPLC) with a wavelength ultraviolet detection at $254 \mathrm{~nm}$. The appearance of chromatographic signal at $254 \mathrm{~nm}$ was related to $\pi-\pi *$ transition in the conjugated systems, such as aromatic compounds that make up the solution of the dye RO16. Figures 10 (I-IV) shows the solution chromatograms containing (1) RO16 dye untreated $\mathrm{t}=0$ and after electrolysis at $100 \mathrm{~mA} \mathrm{~cm}^{-2}$ current density during: (2) $10 \mathrm{~min}$ and (3) 90 min. For the untreated dye solution (chromatogram 1), at least six aromatic compounds appeared, with different polarities and retention times, named in the chromatograms as peaks from $\mathrm{A}$ to $\mathrm{G}$. The compounds concerning peaks $\mathrm{C}$ and $\mathrm{E}$, due to their proportions, should be directly associated with the reactive RO16 dye. After the first 10 min of electrochemical treatment, at $100 \mathrm{~mA} \mathrm{~cm}$, the disappearance of the two 
(I)

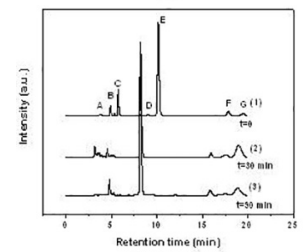

(III)

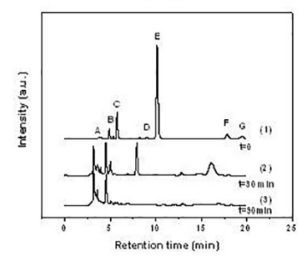

(II)

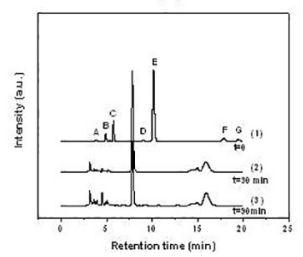

(IV)

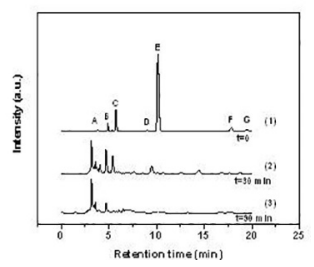

Figure 10. Chromatograms (HPLC, $\lambda=249 \mathrm{~nm}$ ) of the solution RO 16 dye, without treatment, solution after 30 minutes and solution after 90 minutes of treatment at: (I) 25, (II) 50, (III) 75 and (IV) $100 \mathrm{mAcm}^{-2}$.

main peaks related to the dye (C and E) occurred. After 90 min of treatment the emergence of other peaks with lower retention time is observed. This result implies the presence of compounds with more polar characteristics than those for the RO16 dye.

The above observation can be confirmed in Figure 11, which shows the normalized total chromatographic area as a function of the applied current density. In this case, chromatogram peak integrations obtained after each treatment can be considered a measure of the total concentration of aromatic compounds. The results clearly demonstrated the degradation efficiency of the aromatic compounds in solutions containing the RO16 dye, in addition to the by products degradation formed during each process. As the current density increases, the degraded by-products decrease. This reduction in the aromaticity of RO16 dye solution led to the possible formation of compounds of the aliphatic chain. From an environmental standpoint these compounds are very important because they tend to be biodegradable ${ }^{32}$.

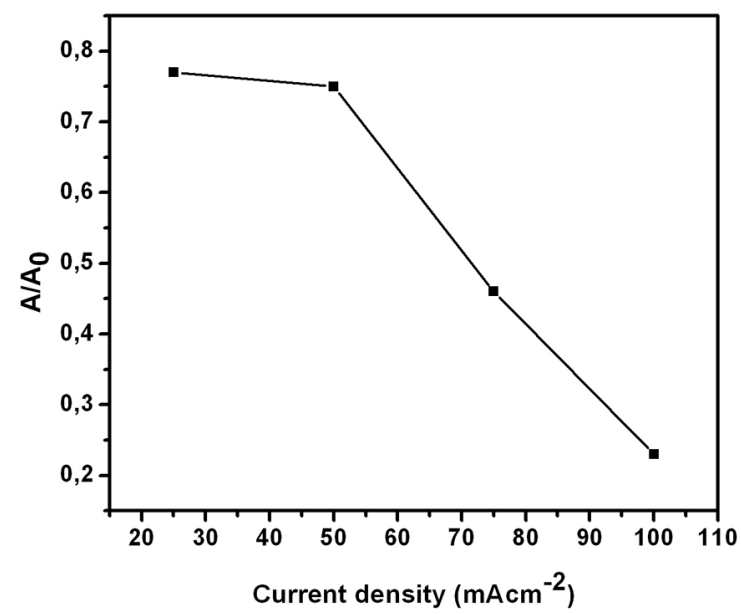

Figure 11. Normalized total chromatographic area as a function of applied current density in each treatment.

\section{Conclusions}

The production, characterization and application of $\mathrm{BDD} / \mathrm{Ti}$ electrode in the electrochemical degradation of the RO16 dye were successfully obtained. The morphological characterization showed the diamond film completely closed without the presence of cracks. The electrochemical treatments showed that BDD electrode was effective in removing the color of the solutions associated to their TOC percentage. The absorption spectrum of RO16 azo-dye revealed a significant decay of the intense orange color of the dye as a function of $\mathrm{pH}$. It was found that alkaline media was more favorable with respect to color removal. The discolor ability of this method in alkaline media probably is due to the RO16 dye deprotonated form, since the results of TOC analysis did not show significant difference in the mineralization of the organic matter concerning $\mathrm{pH}$ variation. The HPLC showed that the intermediates formed during the degradation present more polar character than that for RO16 dye. This indicates that the production of biodegradable compounds is possible during the electrolysis process.

\section{Acknowledgments}

The authors would like to thank FAPESP (Process 2010/18462-2), CNPq and CAPES for the financial support.

\section{References}

1. Guaratini CCI, Zanoni MVB. Corantes têxteis. Química Nova. 2000;23(1):71-78.

2. Anjaneyulu Y, Chary NS, Raj DSS. Decolourization of Industrial Effluents - Available Methods and Emerging Technologies - a Review. Reviews in Environmental Science and Bio/Technology. 2005;4(4):245-273.

3. Pinheiro HM, Touraud E, Thomas O. Aromatic amines from azo dye reduction: status review with emphasis on direct UV spectrophotometric detection in textile industry wastewaters. Dyes and Pigments. 2004;61(2):121-139.

4. Stylidi M, Kondarides DI, Verykios XE. Pathways of solar light-induced photocatalytic degradation of azo dyes in aqueous $\mathrm{TiO}_{2}$ suspensions. Applied Catalysis B: Environmental. 2003;40(4):271-286.

5. Cisneros RL, Espinoza AG, Litter MI. Photodegradation of an azo dye of the textile industry. Chemosphere. 2002;48(4):393-399.

6. Li M, Feng C, Hu W, Zhang Z, Sugiura N. Electrochemical degradation of phenol using electrodes of $\mathrm{Ti} / \mathrm{RuO}_{2}-\mathrm{Pt}$ and Ti/ $\mathrm{IrO}_{2}$-Pt. Journal of Hazardous Materials. 2009;162(1):455-462.

7. Ohsaka T, Shinozaki K, Tsuruta K, Hirano K. Photo-electrochemical degradation of some chlorinated organic compounds on $\mathrm{n}-\mathrm{TiO}_{2}$ electrode. Chemosphere. 2008;73(8):1279-1283.

8. Hu JM, Zhang JQ, Meng HM, Zhang JT, Cao CN. Electrochemical activity, stability and degradation characteristics of $\mathrm{IrO}_{2}$-based electrodes in aqueous solutions containing $\mathrm{C}_{1}$ compounds. Electrochimica Acta. 2005;50(27):5370-5378. 
9. Pera-Titus M, García-Molina V, Baños MA, Giménez J, Esplugas S. Degradation of chlorophenols by means of advanced oxidation processes: a general review. Applied Catalysis B: Environmental. 2004;47(4):219-256.

10. Flox C, Garrido JA, Rodríguez RM, Centellas F, Cabot PL, Arias C, et al. Degradation of 4,6-dinitro-o-cresol from water by anodic oxidation with a boron-doped diamond electrode. Electrochimica Acta. 2005;50(18):3685-3692.

11. Costa CR, Montilla F, Morallón E, Olivi P. Electrochemical oxidation of acid black 210 dye on the boron-doped diamond electrode in the presence of phosphate ions: Effect of current density, $\mathrm{pH}$, and chloride ions. Electrochimica Acta. 2009;54(27):7048-7055.

12. Cheng SA, Fung WK, Chan KY, Shen PK. Optimizing electron spin resonance detection of hydroxyl radical in water. Chemosphere. 2003;52(10):1797-1805.

13. Rajeshwar K, Ibanez JG. Environmental Electrochemistry Fundamentals and Application in Pollution Abatement. San Diego: Academic Press; 1997.

14. Tarr MA, ed. Chemical Degradation Methods for Wastes and Pollutants: Environmental and Industrial Applications. Boca Raton: CRC Press; 2003.

15. Martínez-Huitle CA, Ferro S. Electrochemical oxidation of organic pollutants for the wastewater treatment: direct and indirect processes. Chemical Society Reviews. 2006;35(12):1324-1340.

16. Braga NA, Cairo CAA, Matsushima JT, Baldan MR, Ferreira NG. Diamond/porous titanium three-dimensional hybrid electrodes. Journal of Solid State Electrochemistry. 2010;14:313-321.

17. Grattrell M, Kirk DW. A Study of Electrode Passivation during Aqueous Phenol Electrolysis. Journal of the Electrochemical Society. 1993;140(4):903-911.

18. Mitadera M, Spataru N, Fujishima A. Electrochemical oxidation of aniline at boron-doped diamond electrodes. Journal of Applied Electrochemistry. 2004;34(3):249-254.

19. Martínez-Huitle CA, Brillas E. Decontamination of wastewaters containing synthetic organic dyes by electrochemical methods: A general review. Applied Catalysis B: Environmental. 2009;87(34):105-145.

20. Migliorini FL, Braga NA, Alves SA, Lanza MRV, Ferreira NG. Anodic oxidation of wastewater containing the Reactive Orange 16 Dye using heavily boron-doped diamond electrodes. Journal of Hazardous Materials. 2011;192(3):1683-1689.

21. Askari SJ, Akhtar F, Chen GC, He Q, Wang FY, Meng XM, et al. Synthesis and characterization of nano-crystalline CVD diamond film on pure titanium using $\mathrm{Ar} / \mathrm{CH}_{4} / \mathrm{H}_{2}$ gas mixture. Materials Letters. 2007;61(11-12):2139-2142.

22. Azevedo AF, Corat EJ, Leite NF, Trava-Airoldi VJ. Chemical vapor deposition diamond thin films growth on $\mathrm{Ti}_{6} \mathrm{AL}_{4} \mathrm{~V}$ using the Surfatron system. Diamond and Related Materials. 2002;11(3-6):550-554.

23. Mendes de Barros RC, Corat EJ, Ferreira NG, Souza TM, Trava-Airoldi VJ, Leite NF, et al. Dispersion liquid properties for efficient seeding in CVD diamond nucleation enhancement. Diamond and Related Materials. 1996;5(11):1323-1332.

24. Braga NA, Cairo CAA, Almeida EC, Baldan MR, Ferreira NG. From micro to nanocrystalline transition in the diamond formation on porous pure titanium. Diamond and Related Materials. 2008;17(11):1891-1896.

25. Ager JW, Walukiewicz W, McCluskey M, Plano MA, Landstrass MI. Fano interference of the Raman phonon in heavily borondoped diamond films grown by chemical vapor deposition. Applied Physics Letters. 1995;66(5):616-618.

26. Zhang RJ, Lee ST, Lam YW. Characterization of heavily boron-doped diamond films. Diamond and Related Materials. 1996;5(11):1288-1294.

27. May PW, Ludlow WJ, Hannaway M, Heard PJ, Smith JA, Rosser KN. Raman and conductivity studies of boron-doped microcrystalline diamond, facetted nanocrystalline diamond and cauliflower diamond films. Diamond and Related Materials. 2008;17(2):105-117.

28. Silverstein RM, Webster FX, Kiemle DJ. Identificação Espectrométrica de Compostos Orgânicos. $7^{\mathrm{a}}$ ed. Rio de Janeiro: LTC; 2006.

29. Michaud PA, Panizza M, Ouattara L, Diaco T, Foti $\mathrm{G}$, Comninellis C. Electrochemical oxidation of water on synthetic boron-doped diamond thin film anodes. Journal of Applied Electrochemistry. 2003;33(2):151-154.

30. Ujvári M, Láng GG. On the stability of perchlorate ions against reductive attacks in electrochemical systems and in the environment. Journal of Electrochemical Science and Engineering. 2011;1(1):1-26.

31. Comninellis C, Chen G, eds. Electrochemistry for the Environment. New York: Springer; 2010.

32. Hongwei Y, Zhanpeng J, Shaoqi S. Anaerobic biodegradability of aliphatic compounds and their quantitative structure biodegradability relationship. Science of the Total Environment. 2004;322(1-3):209-219. 